\title{
LA EXPOSICIÓN EN LA CIUDAD DE LEÓN: LA OBRA PÍA NUESTRA SEÑORA LA BLANCA (1700-17911)
}

\author{
MARÍA JosÉ PÉREZ ÁlVAREZ \\ Universidad de León
}

Los niños expósitos forman un colectivo cuyo origen individual es prácticamente imposible de atribuir a un grupo social, aunque, de forma genérica, parece que podemos adscribirlos a las capas más débiles de la sociedad. Pueden ser niños nacidos de una pareja cuya unión está bendecida por la Iglesia; fruto de un encuentro casual ${ }^{1}$; o bien, de una relación estable sin formalizar ${ }^{2}$. Así mismo, podrían haber llegado al mundo en el seno de la pobreza o marginalidad; o en una familia que no tenía problemas económicos, pero que circunstancias para nosotros totalmente desconocidas ${ }^{3}$ les hubieran empujado al abandono del recién nacido ${ }^{4}$. Sea la causa que sea, la consecuencia es evidente: la formación de un grupo que, de haber tenido más posibilidades de sobrevi-

\footnotetext{
1. Las cédulas de niños expósitos que dejan clara la ilegitimidad no son muy elevadas, pero sí suficientes para aducir este motivo como uno de los que propiciaron su abandono «mi padre es estudiante y mi madre una perdida» (26-6-1711); «es hijo de buena madre, el padres no se sabe quien es» (10-10-1741); «su madre es no muy buena y su padre peor, porque ofendieron al Redentor» (1-10-1758). En diciembre de 1737 , dejan a una niña con la siguiente anotación «oriéntenla bien, por el amor de Dios, que su padre no la quiere». Es difícil buscar la causa del pesar que esta mujer refleja en la cédula. ¿Es una hija ilegítima?, ¿no la quieren por ser una niña?; ¿tienen ya demasiados hijos? Libros de Registro de Entradas del Arca de Misericordia.

2. «Me recogerán mis padres cuando se casen» (21-10-1727); «Cuando mis padres se casen vendrán a por mí» (5-12-1746). Libros de Registro de Entradas del Arca de Misericordia.

3. La cédula de una niña que depositaron en el torno, el 18 de agosto de 1701, nos da a entender que procede de una familia acomodada. La abandonaron por ser ilegítima y para que esta circunstancia no pesara sobre el honor de la familia. Libros de Registro de Entradas del Arca de Misericordia.

4. Respecto a las causas del abandono, vid. FERNÁNDEZ UgARTE, María, Expósitos en Salamanca a comienzos del siglo XVIII, Diputación de Salamanca, Salamanca, 1988, p. 86.
} 
vir, podría haber alterado la trayectoria cuantitativa de la población ${ }^{5}$. Precisamente esa cuestión atrajo la atención de los tratadistas de la época ${ }^{6}$, que continuamente pusieron en evidencia las condiciones infrahumanas a las que los pequeños tenían que hacer frente. En ese contexto de denuncia apareció el hospicio de leonés.

El objetivo del trabajo es analizar la exposición en ciudad de León entre $1700 \mathrm{y}$ 1791, es decir, mientras subsistió una única institución dedicada a la acogida de estos niños: La Obra Pía Nuestra Señora la Blanca, también denominada Arca de Misericordia o Casa de Expósitos. La fuente principal que hemos utilizado para estudiar la evolución de los abandonos y la trayectoria de estos niños fue los Libros de Asiento. Para ello realizamos un vaciado total de los datos que aporta cada partida, a fin de reconstruir el pequeño ciclo vital que cada niño recorrió. En total contamos con 8.503 registros, de los cuales el 90,4\% son de niños expósitos y el 9,6\% de acogidos en la Obra Pía.

\section{LOS RECURSOS ECONÓMICOS DE LA OBRA PÍA NUESTRA SEÑORA LA BLANCA}

Comenzaremos haciendo una breve referencia a la infraestructura económica de la institución, para conocer la procedencia de los ingresos y los destinos de las partidas de gastos. A tal fin hemos vaciado las cuentas, de los años que se conservan, que están más próximas al periodo de estudio, concretamente de 1760 a 1792. También contamos con los ingresos de 1650-51, los cuales hemos recogido para analizar los posibles cambios en la contabilidad.

Tabla n 1. Ingresos y gastos de la Obra Pía Nuestra Señora La Blanca (\%)

\begin{tabular}{|c|c|c|c|c|c|c|c|c|}
\hline \multicolumn{2}{|c|}{} & Prebendas & Posesiones & Limosnas & Refacción & $\begin{array}{c}\text { Rentas } \\
\text { urbanas y } \\
\text { rústicas }\end{array}$ & Ventas & $\begin{array}{c}\text { Maravedí } \\
\text { sobre el } \\
\text { azumbre de } \\
\text { vino }\end{array}$ \\
\hline $1650-51$ & 73,5 & 11,4 & 4,8 & & & 10,3 & & 100 \\
\hline $1760-64$ & 44,5 & 2 & 10,1 & 0,1 & 41,7 & 1,5 & 0 & 100 \\
\hline $1765-69$ & 47,7 & 1,3 & 10,5 & 0,2 & 37,2 & 3,1 & 0 & 100 \\
\hline $1770-74$ & 33,7 & 1,9 & 4,6 & 0,2 & 28,7 & 10,5 & 20,5 & 100 \\
\hline $1775-79$ & 15,8 & 0,1 & 0,7 & 0 & 7 & 5,5 & 70,8 & 100 \\
\hline $1781-85$ & 20,9 & 0 & 1,3 & 0,9 & 8,8 & 1 & 67,2 & 100 \\
\hline $1786-88$ & 26,3 & 0 & 2,5 & 0 & 6,2 & 1,6 & 63,4 & 100 \\
\hline $1790-92$ & 29,2 & 0,2 & 0,6 & 0 & 5,8 & 10,4 & 53,8 & 100 \\
\hline TOTAL & 25,2 & 0,4 & 2,4 & 0,2 & 12,4 & 4,8 & 54,5 & 100 \\
\hline
\end{tabular}

5. Álvarez Santaló, León Carlos, Marginación social y mentalidad en Andalucia Occidental. Expósitos en Sevilla (1613-1910), Junta de Andalucía, Sevilla, 1980, p. 44.

6. Vid. Fernández Ugarte, María, Expósitos en Salamanca... pp. 29-42.

7. Esta cifra en Asturias, en la segunda mitad del siglo XVIII, fue el 5,6\%. AnsON CALVO, María del Carmen, «Niños ilegítimos y niños expósitos en las Asturias del siglo XVIII», Actas del III Congreso de la A.D.E.H., Braga, 1991. 


\begin{tabular}{|c|c|c|c|c|c|c|c|c|c|}
\hline \multicolumn{1}{|c|}{} & Niños & Personal & $\begin{array}{c}\text { Manu- } \\
\text { facturas }\end{array}$ & $\begin{array}{c}\text { Infra- } \\
\text { estructura }\end{array}$ & $\begin{array}{c}\text { Inver- } \\
\text { siones }\end{array}$ & $\begin{array}{c}\text { Repara- } \\
\text { ciones del } \\
\text { edificio }\end{array}$ & $\begin{array}{c}\text { Ayudas } \\
\text { a la Casa } \\
\text { Cuna } \\
\text { de Pon- } \\
\text { ferrada }\end{array}$ & $\begin{array}{c}\text { Deudas } \\
\text { pleitos }\end{array}$ & TOTAL \\
\hline $1760-64$ & 81,4 & 1,2 & 0 & 15,9 & 0 & 1,4 & 0 & 0 & 100 \\
\hline $1765-69$ & 61,6 & 2,5 & 0 & 18,4 & 17,1 & 0,5 & 0 & 0 & 100 \\
\hline $1770-74$ & 40,4 & 3,3 & 2,1 & 22,4 & 11,5 & 20,3 & 0 & 0 & 100 \\
\hline $1775-79$ & 42,5 & 2,6 & 15,7 & 14,8 & 2,1 & 14,2 & 8,1 & 0 & 100 \\
\hline $1781-85$ & 56,9 & 11,9 & 4 & 13,5 & 0,2 & 6,5 & 7 & 0 & 100 \\
\hline $1786-88$ & 54,3 & 5,2 & 5,3 & 15,8 & 1,6 & 5,7 & 0 & 12,1 & 100 \\
\hline $1790-92$ & 42,3 & 7,7 & 7,4 & 15,5 & 0 & 0 & 0 & 27,2 & 100 \\
\hline TOTAL & 49,9 & 5,6 & 7,3 & 15,9 & 3,1 & 8,5 & 3,6 & 6 & 100 \\
\hline
\end{tabular}

Fuente: Libros de Cuentas del Arca de Misericordia

La dotación económica del Arca de Misericordia de Nuestra Señora la Blanca pasó de depender íntegramente de la caridad del Cabildo a tener cierta autonomía. En un primer momento, 1650-51, la supeditación de la filial respecto al Cabildo fue absoluta, como refleja la distribución de los ingresos. En conjunto, las prebendas ${ }^{8}$ y posesiones ${ }^{9}$ suponían casi el $85 \%$ del dinero recaudado para sufragar los gastos de los infantes (tabla $\mathrm{n}^{\mathrm{o}} 1$ ). Un siglo después, las fuentes de sostenimiento de la Obra Pía ya son mucho más variadas. Esta parcela del Cabildo fue formando un pequeño patrimonio que le proporcionaba destacados beneficios, sobre la base de bienes raíces y la entrada en el mercado del dinero. De todas formas hay que señalar que, si por un lado, el incremento de dicho patrimonio, rural y urbano, no se dejó de lado -por ejemplo en 1766 compraron un prado que pasó a rentarle 90 reales/año-; por otro, los ingresos emanados de este capítulo estuvieron sujetos a continuas modificaciones, debido a nuevas inversiones, ventas, etc.

La contabilidad del Arca recibirá un impulso importante en el último cuarto de la centuria dieciochesca, a raíz de la concesión, en 1772, de lo que se llamó el maravedí sobre el azumbre del vino ${ }^{10}$, que proporcionó a la institución un importante desahogo

8. Estas prebendas fueron incorporadas a la casa de misericordia en 1634. Tras la reforma llevada a cabo por el Papa Urbano VIII quedaban vacantes, en el Cabildo leonés, trece prebendas y media, de las cuales dos fueron incorporadas a la casa de niños expósitos. VILLACORTA RODRÍGUEZ, Tomás, El Cabildo de la Catedral de León. Estudio Histórico-Jurídico, siglos XII-XIX, Archivo Histórico Diocesano, León, 1974, p. 5.

9. Los derechos de posesión se refieren al dinero que debían de pagar las altas dignidades catedralicias cuando pasaban a ocupar un cargo.

10. A.H.D.L. Lib. 218. «Arbitrio del maravedí en azumbre de vino que se vende al por menor en esta provincia, concedido por Su Majestad desde el año 1772 hasta el 75 inclusive...». Un impuesto similla, y con la misma finalidad, fue concedido en Valladolid, en 1757. Vid. EGIDO, Teofanes, «Aportación al estudio de la demografía española: los niños expósitos de Valladolid (siglos XVI-XVII)», en Actas de las I Jornadas de Metodología Aplicada a las Ciencias Históricas. Vol. III, Santiago, 1973, 335-340, p. 340 
económico. El porcentaje que representaba el dinero procedente de este capitulo, una vez consolidado, estuvo siempre por encima del 50 por ciento. Esa nueva fuente de ingresos no sólo aportó estabilidad económica a la casa, sino que dio un giro importante al proceso de captación de expósitos del entorno rural. Desde 1664, al menos, cada vez que las justicias de fuera de la ciudad enviaban al Arca a un niño tenían que comprometerse a sufragar su lactancia o parte de ella, en caso de no disponer de bienes ${ }^{11}$. A partir de $1772^{12}$ los pueblos que contribuían ${ }^{13}$ con el citado impuesto quedaban exentos, ya que todos los gastos que generara el infante eran asumidos por la Obra Pía.

Respecto a los gastos, dos son las partidas que acaparaban más dinero, las crianzas y el grupo que hemos englobado, o en algunos casos nos venía englobado, bajo el epígrafe «otros» o «gastos extraordinarios», y que son los que se refieren al mantenimiento de toda la infraestructura interna de la casa, es decir, leña, ropa para los niños, botica, capellán, etc. La concesión del Arbitrio del vino dio un nuevo y renovado empuje al funcionamiento de la Casa de Expósitos, que se refleja tanto en el impulso que recibió la factoría de hilados, que pertenecía a la Obra Pía, como en la dinámica interna de la Institución. Respecto al taller, entre 1774 y 1776, se invirtió una suma considerable de dinero en la compra de un telares ${ }^{14}$, una sierra o materia prima para su transformación (lino, lana algodón, madera..); e incluso, durante algo más de un año, se contrató a una maestra alemana para «enseñar a hilar fino». Al año siguiente, en 1777, también prestaron servicios al taller un maestro lanero, un maestro tejedor, un cardador o una peinadora de lana. Toda esa infraestructura que se monta en torno a las hilazas rápidamente será productiva, y podemos cuantificar su rendimiento en las partidas de ingresos, que pasan de los 3.785 reales, en 1775 , a los 7.868 reales, en 1775 .

\section{EVOLUCIÓN CUANTITATIVA DE LOS EXPÓSITOS ENTRE 1700 Y 1791}

Analizando la serie en conjunto se comprueba como la trayectoria que experimentaron los ingresos de niños abandonados en la Casa de Expósitos de León fue de signo positivo (Gráfico $n^{0} 1$ ). Comenzamos con una media de 64,3 niños/ año, entre 1700-09, a continuación se presentan tres decenios en los que hay un ascenso progresivo, pero

11. Se trata de un comportamiento idéntico al de Valladolid. EGIDO, Teofanes, «Aportación al estudio de la demografía española... p. 340.

12. En agosto de 1772 es la primera vez que no se recoge el dinero enviado para la crianza del infante. Se trataba de un niño que había aparecido en una Iglesia de La Bañeza. «No se recogen los 6 ducados por estar determinado por el Cabildo, atendiendo al arbitrio del maravedí en azumbre de vino». Libro Registro de Entradas del Arca de Misericordia.

13. Los niños que aparecían en los pueblos que no contribuían con el citado impuesto no eran recibidos en el Arca. Es, por ejemplo, el caso de una niña que llevaron el 22 de diciembre de 1774, y que había aparecido en Corcos, jurisdicción de Almansa. «No se la quiso recibir por el Señor Administrador, por tocar dicho lugar y jurisdicción a la provincia de Valladolid.... Pues de ningún modo puede ni debe recibir a los niños de los pueblos no contribuyentes al maravedí en azumbre de vino..». Finalmente y por el peligro que la niña corría el Administrador la recogió. Libro Registro de Entradas del Arca de Misericordia.

14. A.H.D.L. Lib. 218. 


\section{Gráfico n 1. Ingresos en la Casa de Expósitos de León (1700-1791)}

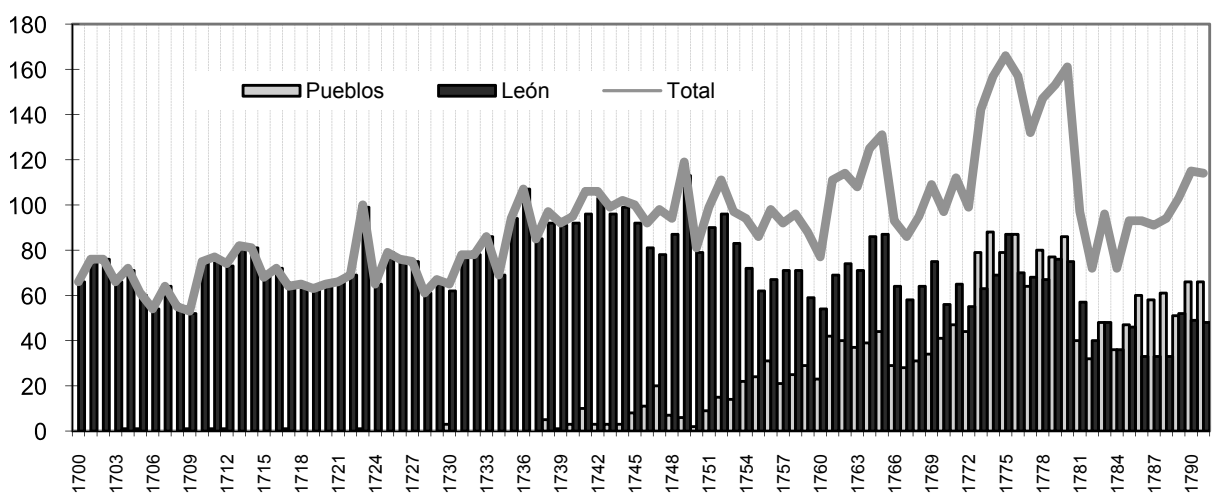

Fuente: Libros de Registro de Entradas del Arca de Misericordia

no excesivamente alarmante. A partir de la década de los cuarenta, en que ya se reflejan tímidamente los niños del resto de la provincia, la media de ingresos por año ya ronda el centenar, alcanzándose el punto máximo en la década de los 70 , concretamente en los últimos cinco años, momento en que se llega a las 151 exposiciones.

Para aproximarnos a la incidencia demográfica ${ }^{15}$ que tuvo el fenómeno de la exposición en la ciudad de León hemos comparado el número de expósitos oficialmente de la capital - que asciende a 6.537-, con los bautismos registrados entre 1700 y 1791 en las siete parroquias mayores de la ciudad ${ }^{16}$, que representan el $68 \%$ del vecindario. Entre las curvas de bautismos y abandonos se observan algunas coincidencias, aunque sólo en lo referente a la tendencia y no en cuanto a niveles. Ambas describen una trayectoria paralela: ascendente en la primera mitad de siglo y descendente en la segunda. Sin embargo, si comparamos la base poblacional de la ciudad con el nivel de exposiciones, y considerando que el flujo de entradas en el arca no variaría de forma muy brusca durante todo el período, debemos concluir que el peso de los abandonos es excesivo, sobre todo en la primera mitad de siglo. Tengamos en cuenta que durante esa etapa son varios los años en que las exposiciones supondrían más del 70\% de los bautismos. Tales resultamos son muy elocuentes aún teniendo en cuenta que bautismos y exposiciones no siempre cabalgan a la $\operatorname{par}^{17}$ (gráfico $\left.\mathrm{n}^{0} 2\right)$.

Partiendo del hecho de que las cifras de población en la capital leonesa eran prácticamente las mismas en la década de los ochenta del siglo XVIII que en los primeros

\footnotetext{
15. Para realizar este cálculo hemos seguido un método similar al empleado para Granada por DE LA FUENTE GALÁn, María del Prado. Marginación y pobreza en la Granada de la segunda mitad del siglo XVIII. Los niños expósitos, Universidad de Granada, Granada, 2000, p. 176 y ss.
}

16. San Martín, Santa Ana, El Mercado, San Juan de Regla, Santa Marina la Real y Palat de Rey.

17. De La Fuente Galán, María del Prado. Marginación y pobreza en la Granada.... p. 181. 
años de la centuria ${ }^{18}$, la pregunta que surge es: ¿cuál es la razón que puede explicar un descenso tan importante de exposiciones en la segunda mitad?. La respuesta más lógica nos induce a considerar que la información que registra la fuente está distorsionando aquella realidad. Durante la primera mitad de siglo, los datos de la Obra Pía esconden un número significativo de niños que no eran naturales de la ciudad. Al no existir el arbitrio del vino la institución no tenía obligación alguna con los pequeños abandonados en el ámbito rural. En consecuencia, muchos de ellos serían transportados a León, por sus padres u otras personas, y depositados sin ningún signo distintivo que les identificara como foráneos ${ }^{19}$. Cuando el arca comenzó a recaudar el impuesto, los progenitores ya no tenían que recurrir a esa relativa clandestinidad ${ }^{20}$, podían dejarlos en su localidad de origen o en otra próxima, puesto que sabían que sus hijos iban a ser conducidos y admitidos en la Obra Pía. Otro dato que viene a corroborarnos este razonamiento es que, exceptuando los diez primeros años de la serie que arrojan una media de 64 abandonos, en el resto de los decenios, hasta que comienzan a identificarse los forasteros, ésta supera holgadamente los 70, llegando incluso a los 90 anuales. Esta tendencia cambia significativamente en el momento en que el comienzan a registrarse niños del área rural. La ciudad de León en 1752 tenía 5.556 habitantes, y ese año entraron en la casa de expósitos 96 niños. Por su parte, la Cazalla de mediados del XIX contaba con casi 800 habitantes más y abandonaba unos 65 pequeños por año. En esa localidad andaluza, después de cruzar las tasas brutas de natalidad con los abandonos, resultaría que los padres habrían renunciado a casi un tercio de los nacidos ${ }^{21}$. En León esa misma cifra ascendería al 47,6\% ${ }^{22}$. Pues bien, si Álvarez Santaló juzga el comportamiento sevillano como inverosímil e inviable, y sólo justificable por el ingreso de niños forasteros, menos creíbles serían todavía las cifras leonesas.

Retomando el análisis sobre el volumen de asistencias en la Obra Pía podemos dividirla en tres partes. La primera abarcaría desde 1700 hasta 1739 . La media de

18. RUBIo PÉREZ, Laureano Manuel, León, 1751. Según las Respuestas Generales del Catastro de Ensenada, Tabapress, Madrid, 1993, p. 61.

19. A continuación ponemos una serie de ejemplos que nos ayudan a justificar este razonamiento: El 25 de noviembre de 1739, fue abandonada en el arca una niña que salió a criar a Manzaneda de Torio. En esa localidad la recogió un vecino de Campohermoso en nombre de sus padres. Asimismo, el 10 de julio de 1742, se presentaba en la Obra Pía un vecino de Santa Colomba a recoger una niña que había sido expuesta en la ciudad y de la cual dijo ser pariente. El 29 de mayo de 1762, se depositó un niño en el torno en cuya cédula ponía: «se ha de dar a criar hacia la Robla o la Pola, por estar su padre inclinado hacia ese país». ¿No estarían esas localidades próximas a su pueblo de origen, o incluso, no procedería de alguna de ellas?. Libro Registro de Entradas del Arca de Misericordia.

20. Clandestinidad relativa y puntual, ya que no sería precisamente la discreción la que rodeaba al mundo de la exposición. Vid. MARCOS MARTíN, Alberto, «Infancia y ciclo vital: el problema de la exposición en España durante la Edad Moderna» en De esclavos a señores, Universidad de Valladolid, Valladolid, 1992, 43-68, p. 59.

21. Álvarez Santaló, León Carlos, Marginación social y mentalidad en Andalucía ... p. 78.

22. Este resultado se ha calculado sobre una tasa de natalidad del 36,3\%o. Vid. PÉrEz GARCíA, José Manuel, «Demografía leonesa en el Antiguo Régimen (1500-1850)», en RUBIo PÉREZ, Laureano Manuel, (Cood.): Historia de León, Vol. III. Universidad de León, León, p. 198. 
ingresos del periodo fue de 73,5 niños - unos 19 puntos por debajo de la media global-, de éstos, 73,1 eran de la ciudad y solamente el 0,4 de la provincia, por lo que la curva la describen las exposiciones, oficialmente, de la ciudad. Sólo hubo cuatro años que superaron el promedio de la serie: 1723, 1735, 1736 y 1738. De forma genérica, los valores tienden al alza, surcados por periodos de estabilidad, recesos y momentos en que el ritmo de ingresos aumentó notablemente. Las mayores convexidades se reflejan entre 1711-1714, en 1723 y 1735-36.

Una segunda etapa, comprendería de 1740 a 1769 . La media del periodo es de 100,1 ingresos (79,6 de la ciudad y 20,5 el resto). Las entradas del 76,7 de los años se colocaron por encima de la media de la serie. Estas tres décadas vienen marcadas por el descenso de los ingresos de niños oficialmente considerados de la ciudad, adquiriendo cada vez mayor representatividad los procedentes de la provincia: su presencia osciló entre el 7,3\%, de 1740-49, y el 33,2\%, de 1760-69. El segundo rasgo definitorio del ciclo procede del apreciable incremento porcentual de los depósitos, o acogimientos temporales, en los que se entremezclan niños legítimos con ilegítimos (Gráfico $n^{\circ} 3$ ). De todos modos, las exposiciones continúan dominando el panorama, ya que representaban entre el 89,8 y el 97\% las asistencias. En cuanto a los asilos temporales, comenzaron siendo muy esporádicos y hasta la década de los cuarenta la media no pasó de 1 niño por año, pero a partir de este momento comenzó a generalizarse el fenómeno: de una media de 3 , entre $1740-49$; pasamos a 2,4 , de entre 1750 a 1759 ; y ya a 10,7 , en la década de los sesenta.

La última fase se iría de 1770 a 1791 . En ella se inserta la década que registró los mayores volúmenes de entrada, 1700-177923, que no de exposiciones, ya que mientras la media de éstas se situó en 93,7, la de los albergados pasó a ser de 42,5. Excepto los años 1782, 1784 y 1787, en que las entradas estuvieron por debajo de la media secular, los demás la superan holgadamente. Todas estas circunstancias dieron como resultado el que en esta etapa se alcanzaran los 116,4 ingresos/año (55,7 de la ciudad y 60,7 del campo). Así mismo, los niños acogidos llegan a representar entre el 15,9\% y el 31,2\% de las entradas. En contrapartida, y lógicamente, las exposiciones decaen, oscilando entre el $68,8 \%$ y el $84,1 \%$. Por lo tanto, en este momento pasan a dibujar el movimiento de la curva los niños acogidos y los forasteros. Estos últimos, que como ya hemos dicho comenzaron a declararse tímidamente en la década de los cuarenta, ahora pasan a representar casi el $50 \%$ de los ingresos ${ }^{24}$.

La directriz secular se presta a ciertas precisiones. Si separamos los niños en función de su lugar, oficial, de procedencia, León o provincia, se comprueba como a partir de la década de los cincuenta se marca un punto de inflexión. La evolución en la ciudad es a la baja mientras que en el campo es al alza. Ascenso propiciado por

23. En la Casa de Expósitos de Ponferrada, que comenzó a funcionar en 1775, se alcanzó uno de los mayores volúmenes de ingresos entre 1776 y 1783. LÓPEZ CANEDA, Ramón, Expósitos e ilegítimos en Valedoras y el Bierzo (1700-1825), Instituto de Estudios Valdeorrenses, Valedoras, 2003, p. 75.

24. En el global de la serie representan el 23,1\%. Si los cálculos los realizamos sólo a partir de 1740, entonces la cifra pasa a ser del 35\%, y restringiéndolos a 1770-1791, el 47,9\%. 
factores intrínsecos, como sería el aumento de población y las coyunturas económicas, y extrínsecos, donde se incluiría la concesión al Arca del impuesto sobre el vino, en 1772. Esta prebenda obligó a la Obra a recoger a todos los expósitos de las localidades de la provincia que estuvieran sometidas a ese impuesto. A partir de esa fecha, el flujo de desplazamientos de niños de la provincia hacia la ciudad comenzó a ser masiva ${ }^{25}$.

A continuación analizaremos en conjunto el ritmo de ingresos, para ver en qué medida éstos pueden derivar de factores demográficos y/o problemas económicos, aún teniendo en cuenta que estas circunstancias no eran las únicas que podían propiciar el abandono de un niño ${ }^{26}$. En las décadas de los treinta y cuarenta del siglo XVIII en la provincia de León se entrelazaron periodos de crisis y de estancamiento agrícola. La coyuntura recesiva se inició en 1731 y se prolongó hasta los años cincuenta, arrastrando a la miseria a muchas familias ${ }^{27}$; y, precisamente, en esos años se aprecia un aumento en el abandono de niños. Otro tanto podríamos decir de los sesenta, década en la que el descenso de producción tuvo repercusiones negativas en al ámbito rural y urbano ${ }^{28}$. En ese decenio el momento en el que se produjo un mayor incremento de ingresos fue entre 1761 y $1765^{29}$.

Hemos cotejado los bautismos de la ciudad con las entradas de niños «oficialmente» de León y aunque somos conscientes de que esta curva se ve un tanto distorsionada por la presencia en ella de forasteros, hemos intentado aproximarnos a la relación que existió entre coyunturas económicas y abandonos. En primer lugar, se constata como la crisis de la década de los cuarenta tuvo graves repercusiones sobre los recién nacidos (Gráfico $\mathrm{n}^{0}$ 2). Es éste uno de los momentos en que más se alejan las curvas de bautismos y exposiciones ${ }^{30}$, con inevitables efectos negativos para los pequeños: la crisis

25. MARCOS MARTín, Alberto, «Infancia y ciclo vital: el problema de la exposición ..., p. 65-66. Este autor nos pone varios ejemplos de Hospicios en los que el desahogo económico de la institución, por la concesión de un determinado impuesto u otros motivos, supuso a partir de entonces una entrada masiva de niños.

26. Son muchas las cuestiones que influyeron a la hora de que los padres tomaran una decisión de este tipo, como por ejemplo, la escasa valoración de la infancia. Vid. FERNÁnDEZ UGARTE, María, «Los marginados familiares. Los expósitos: el modelo de Salamanca» en Montojo MonTojo, Vicente (ed.), Linaje, familia y marginación en España (ss. XIII-XIX), Universidad de Murcia, Murcia, 1992, p. 132

27. En esos años, en La Bañeza se incrementó el número de exposiciones derivadas de las dificultades económicas de la población. PÉREZ, Laureano Manuel, La Bañeza y su tierra, 1650-1850, Universidad de León, León, 1987, p. 163; por su parte, PÉREZ GARCÍA, José Manuel, establece una relación entre crisis de subsistencia, ilegitimidad y, por extensión, abandonos. «La mortalidad infantil en la Galicia del siglo XIX. El ejemplo de los expósitos del Hospital de los Reyes Católicos de Santiago», Estudios Compostelanos, 4, 1976, 171-1197, p. 178.

28. RuBio PÉREZ, Laureano M., León $1751 \ldots$, p. 60

29. El 11 de mayo de 1764, la ciudad de León pedía al cabildo catedralicio «traer a la milagrosa imagen de Nuestra Señora del Camino en rogativa, con motivo de la gran falta de agua que se padece». A.C.L. Libro de Actas.

30. En Salamanca, la relación entre abandonos y crisis económicas fue muy estrecha, pero no hubo un acoplamiento perfecto. FERNÁNDEZ UGARTE, María, «Los marginados familiares. Los expósitos...p. 133. En Granada, durante las crisis económica de 1630-40, las exposiciones aumentaban a medida que 


\section{Gráfico $n^{0}$ 2. Trayectoria cuantitativa de los Bautismos abandono de niños en la ciudad de León}

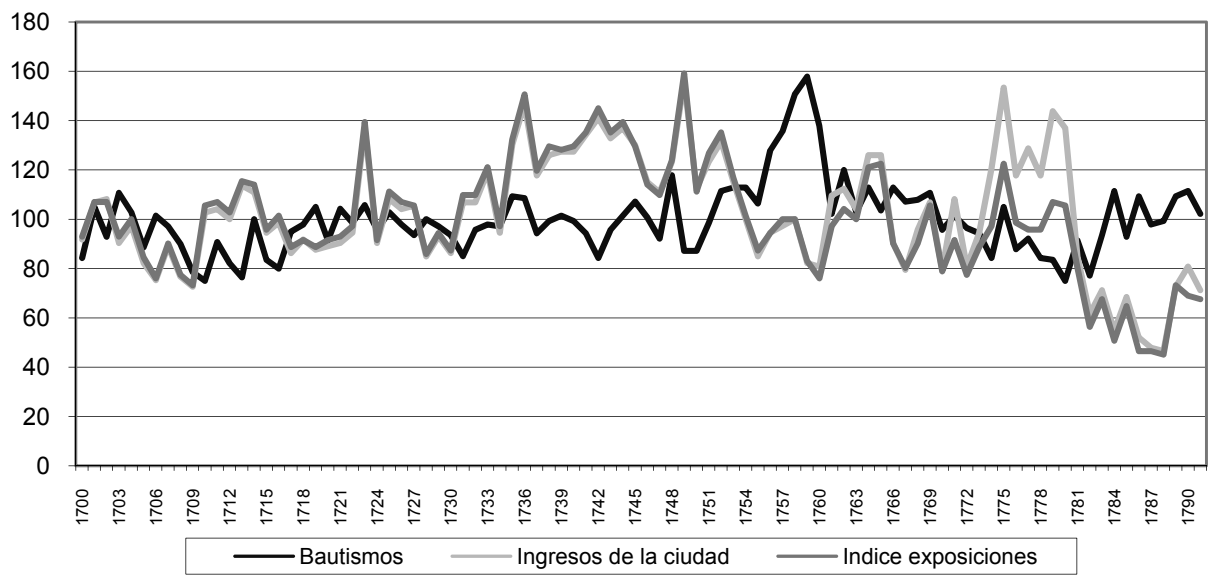

económica obligó a muchas familias a deshacerse de bocas que no podían alimentar ${ }^{31}$. Por su parte, el descenso de abandonos entre 1715 y 1720 y el de los años cincuenta, vendría propiciado por las buenas cosechas ${ }^{32}$. En estas etapas apreciamos nuevamente una notable distancia entre las curvas, significando mejores expectativas para la infancia: la bonanza económica frenó los ingresos en el arca.

El binomio buenas cosechas descenso de ingresos y a la inversa, no tiene un acoplamiento perfecto en todos los momentos. Es el caso de los primeros años del siglo XVIII, cuando tuvo lugar un ciclo agrícola recesivo que llegó hasta 1711. La centuria se inició con una media de ingresos de 71,2 , en el primer quinquenio y 57,4 , en el segundo. Ese descenso nada tiene que ver con los niveles de producción, ya que entre 1705-1709 aún seguían estancados. La bajada en el ritmo de abandonos sería consecuencia pues del descenso de nacimientos en esos cinco años. Una vez que la producción se recupera, a partir de $1711^{33}$, el promedio de ingresos de los cinco años en que se inserta esa fecha, lejos de descender, que sería lo esperado al mejorar la situación

descendían los bautismos. SÁNCHEZ-MONTES GONZÁLEZ, Francisco, La población granadina en el siglo XVII, Universidad de Granada, Granada, 1989, p. 102-104.

31. El paralelismo entre coyunturas económicas recesivas y aumento del fenómeno de la exposición ha sido puesto de manifiesto por numerosos trabajos. ABREU, Laurinda, «Un destin exceptionnel: les enfants abandonnés au travail (Évora, 1650-1837)», Annales de Démographie historique, 2, pp. 165-183, pp. 167-169.

32. RuBio PÉREZ, Laureano M., La Bañeza y su tierra ... p. 243.

33. RuBio PÉREZ, Laureano M., Producción agraria en la zona norte castellano-leonesa durante la Edad Moderna, Universidad de León, León, 1986. p 49. 
económica, aumentó hasta los 77,8 $8^{34}$. Tal incremento de exposiciones podemos, con un cierto retraso ${ }^{35}$, encuadrarlo con la crisis de subsistencia que, a nivel nacional, se desarrolló entre 1708 y $1710^{36}$. De hecho, si nos basamos en los niños que tienen anotada la edad en la cédula, comprobamos que durante este quinquenio es cuando entran más criaturas que superan el $a_{n} \mathrm{n}^{37}$. Son aquellas que habían nacido en una coyuntura marcada por las dificultades económicas: sus padres, apegados a una esperanza, los criaron hasta que la realidad de las cosechas, que no acababan se estabilizarse, les obligó a desprenderse de ellos.

Tampoco esa coincidencia entre malas cosechas y exposición se produjo en el bienio 1767-68 ${ }^{38}$. En el primero de esos años el número de ingresados descendió notablemente respecto a los del primer quinquenio de la década. Se pasó de más del centenar de exposiciones, entre 1760 y 1765, a 93, en 1766 y 86 en 1767. Al año siguiente, en que de nuevo la cosecha fue calamitosa, ingresaron 95 niños. Las verdaderas consecuencias de esos difíciles años se manifestaron en 1769, momento en que, otra vez, los abandonos pasan del centenar.

En el mundo de las exposiciones, al lado de los factores económicos actuarían otros de carácter demográfico. El gran número de abandonados y acogidos de la segunda mitad del siglo XVIII ${ }^{39}$ sería consecuencia del incremento de población que tuvo lugar en la provincia de León, después de la década de los cincuenta ${ }^{40}$, así como del

34. Este comportamiento leonés es similar al de Úbeda. TARIFA FERNÁNDEZ, Adela, Pobreza y asistencia social en la España moderna: la Cofradia de San José y Niños expósitos de Úbeda (siglos XVI-XVIII), I.E.G., Jaén, 1994. pp. 111-112.

35. También en Oviedo el incremento de ingresos se producía con un cierto retraso temporal respecto a las crisis. ANSON CALVO, María del Carmen, «Niños ilegítimos y niños expósitos en las Asturias....

36. EIRAS RoEl, Antonio, La población de Galicia. 1700-1860, Fundación Caixa Galicia, Santiago, 1996, p. 88. BARREIRo MALlón, Baudilio, La Jurisdicción de Xallas en el siglo XVIII: población, sociedad y economía, Universidad de Santiago, Santiago 1973, p. 225.

37. En la casa cuna Sevillana, durante los años económicamente complicados, aumentaban los ingresos de niños «mayorcitos». Álvarez SANTALÓ, León Carlos, Marginación social y mentalidad en Andalucia... p. 87.

38. RUBIO PÉREZ Laureano M., «Tierra y agricultura, estructuras, distribución y usos del espacio productivo», en RUBio PÉREZ, Laureano M. (coor), Historia de León, Universidad de León, León, 1999, p. 336.

39. A factores demográficos achacan el aumento de exposiciones en Canarias en la segunda mitad del siglo XVIII. Lobo CABreRA, Manuel, LóPEZ CANEDA, Ramón y TORRES SANTANA, Elena, La «otra» población: expósitos, ilegítimos, esclavos. (Las Palmas de Gran Canaria. Siglo XVIII), Universidad de Las Palmas, Las Palmas, 1993, p. 37. También en Asturias tuvo lugar un aumento de ingresos en la segunda mitad del siglo XVIII. ANSON CALVO, María del Carmen, «Niños ilegítimos y niños expósitos en las Asturias... Álvarez Santaló, León Carlos, Marginación social y mentalidad en Andalucía... p. 48, Considera que existe una proporcionalidad entre abandono de niños y tamaño de la población.

40. PÉREZ GARCÍA, José Manuel, «Demografía leonesa en el Antiguo Régimen... p. 197. 
aumento de la ilegitimidad, sobre todo en la áreas urbanas $^{41}$ y en la Montaña ${ }^{42}$. La ampliación de efectivos demográficos no estuvo acompañada de las condiciones económicas necesarias para poder reabsorberlos ${ }^{43}$. En la década de los setenta, los periodos de bonanza agrícola ${ }^{44}$ no tuvieron la suficiente entidad como para evitar que se contuvieran unos precios en continua subida, especialmente desde que fue abolida la tasa de los granos.

En los años finales de los sesenta y en los setenta, constatamos un hecho que no hemos encontrado anteriormente ni se volverá a repetir y que nos da muestra de la penuria en que se vivía: el arca tuvo que recoger a varios niños que anteriormente habían sido entregados en adopción, porque sus familias no podían mantenerlos ${ }^{45}$. A su vez, en los dos quinquenios que conforman la década de los setenta, se alcanzaron las medias de ingresos más elevadas de la serie: 121,4 y 151 respectivamente. Una palpable evidencia del hacinamiento ${ }^{46}$ que sufría el arca y de la escasez de nodrizas externas es el siguiente testimonio: cuando en agosto de 1778 se pretendía ingresar a un niño procedente del concejo de Omaña, el administrador se vio obligado a remitirlo a la justicia de su lugar de origen, con el fin de que fuera ésta la que se encargara de buscarle un ama, comprometiéndose la Obra Pía a sufragar los gastos que ocasionara la crianza. De ese contexto económico que acabamos de reseñar derivaría una pobreza aún mayor en aquellos grupos sociales que vivían al límite de la subsistencia. En el gráfico $n^{\circ} 3$, se puede comprobar como a consecuencia de las dificultades económicas, la Obra Pía acogía los mayores porcentajes de depósitos en la década de los setenta, concretamente el $31,2 \%$. Se trata de niños legítimos e ilegítimos cuyas familias, a causa del infortunio, justificaban no poder hacerse cargo de ellos. Pero en estos momentos, gracias al impuesto sobre el vino, las familias ya no necesitaban exponerlos, bastaba con justificar ante las autoridades la miseria familiar.

De todas formas, y a pesar de las coincidencias que existen entre los indicadores económicos y la exposición, consideramos no debe menospreciarse la fuerza que tendría la evolución demográfica. Muchos expósitos son fruto de embarazazos no deseados y éstos pueden producirse en cualquier momento, pero, indudablemente, la posibilidad de que aumenten es proporcional al tamaño de la población.

41. RUBio PÉRez Laureano M., La Bañeza y su tierra... p. 289. BARTOlOMÉ BARTOLOMÉ, Juan Manuel, Vino y viticultores en el Bierzo, Universidad de León, León, 1996, p 289.

42. PÉrez Álvarez, María José, La Montaña Noroocidental leonesa en la Edad Moderna, Universidad de León, León, 1996, p. 280.

43. Marcos Martín, Alberto, España en los siglos XVI, XVII y XVIII. Economía y sociedad, Critica, Barcelona, 2000, p. 585

44. Muy buenas fueron las cosechas de 1774 y 1777. RUBIo PÉREZ, Laureano M., Producción agraria en la zona norte castellano-leonesa .... p. 50

45. Hemos encontrado 13 casos de niños que recoge la casa porque iban con sus familias «de puerta en puerta». 1 caso en $1768 ; 1$, en $1769 ; 3$, en $1770 ; 2$, en $1772 ; 1$, en 1773 ; y 5 , en 1774.

46. «Por hallarme con muchos niños y pocas amas». Libros de Registro de Entradas del Arca de Misericordia. 


\section{Gráfico n 3 . Tipología de los niños ingresados (1700-1791)}

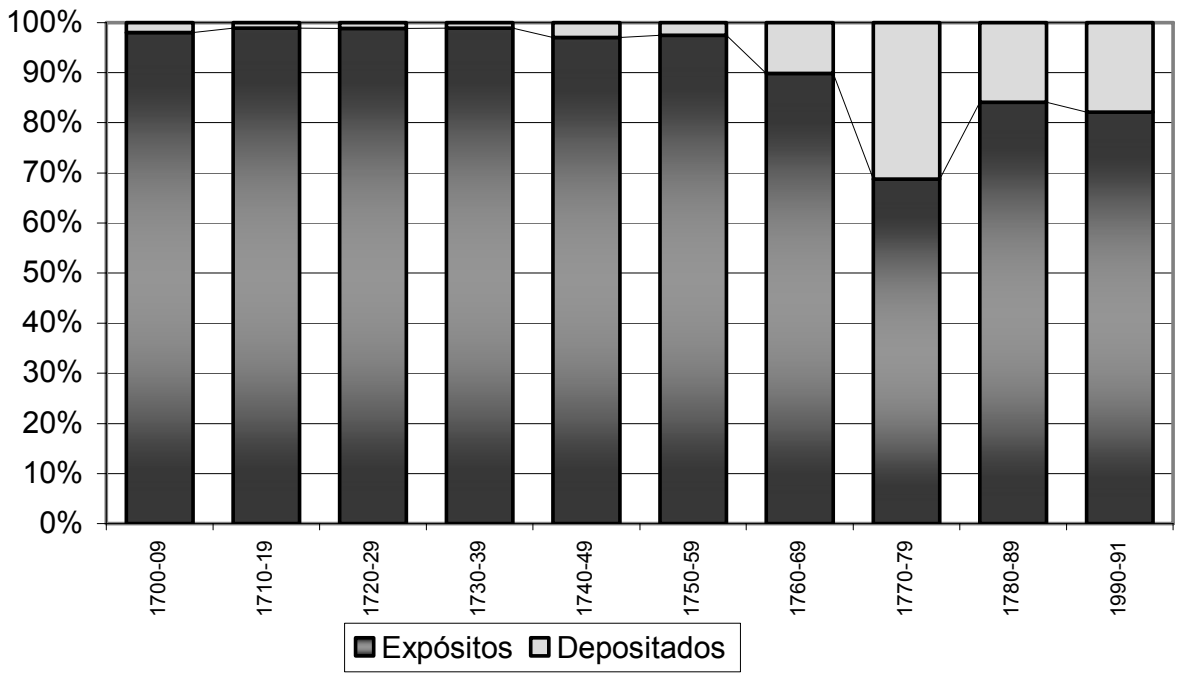

Fuente: Libros de Registro de Entradas del Arca de Misericordia

\section{ESTACIONALIDAD DE LOS INGRESOS}

El análisis de la evolución mensual de las entradas, en relación con el nacimiento y concepciones, nos permitirá conocer si las exposiciones tuvieron alguna relación con las estructuras económicas o con factores de otro orden, como pueden ser los religiosos, biológicos, lúdicos, etc.

Conocemos la edad del $20 \%$ de los niños que ingresaron en las casas de la provincia. De ellos, el 78,1 \% tenían menos de un mes de vida, y del 21,9\% restante, había niños que superaban el año. El conocimiento de la fecha exacta de nacimiento del pequeño resulta imprescindible para el análisis de las concepciones, sin embargo, en nada influirá si lo que pretendemos es medir el mes de abandono. Cuando en la cédula se especifica el día del nacimiento del niño no existe ningún tipo de problema pero, en cambio, si la edad que refleja es meramente aproximativa corremos el peligro de asignarle erróneamente el mes de llegada al mundo. Para intentar neutralizar, en la medida de lo posible, estas incidencias, por ser muy abundantes los segundos casos, hemos decidido analizar los abandonos por estaciones ${ }^{47}$ y no mes a mes.

Una vez justificado este método de trabajo podemos ya presentar los resultados obtenidos. En primer lugar se constata que el modelo estacional es muy similar en el

47. Hemos seguido el esquema plenamente justificado ya en otros trabajos. DE LA FuENTE GALÁN, María del Prado, Marginación y pobreza en la Granada... y Fernández UGARTE, María, Expósitos en Salamanca... p. 75. 


\section{Gráfico n 4. Estacionalidad en los ingresos (1700-1791)}

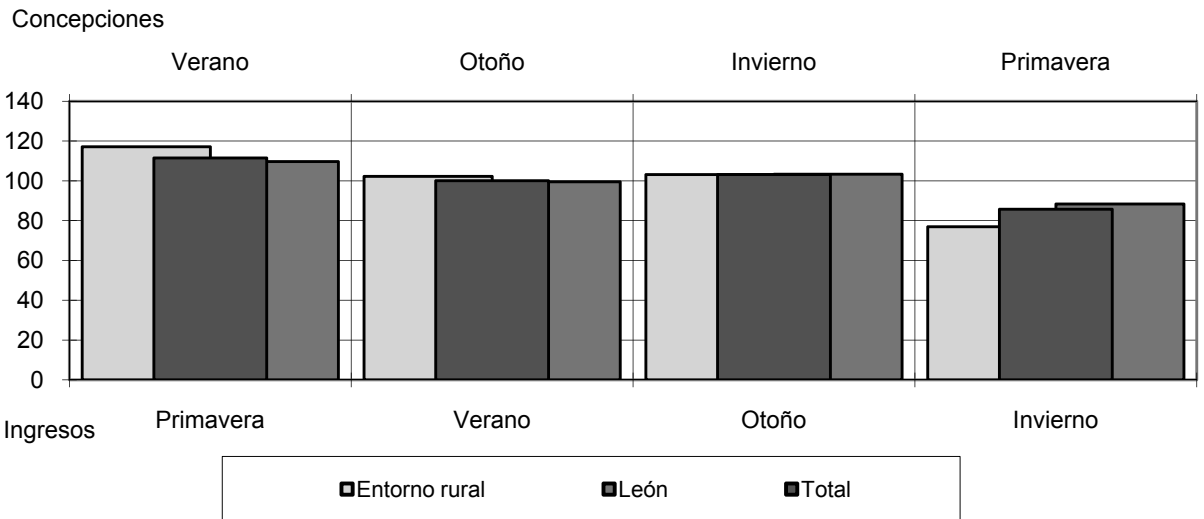

Fuente: Libros de Registro de Entradas del Arca de Misericordia

mundo rural y urbano, con mayores oscilaciones en el primero (Gráfico $\mathrm{n}^{\circ} 4$ ). La menor cifra de abandonos tenía lugar en el invierno, concretamente en el mes de diciembre. Dos pueden ser las circunstancias que provocarían ese descenso de ingresos: por un lado, la proximidad temporal a la cosecha y, por otro, la caída de los nacimientos consecuencia del retraimiento de las concepciones en la Cuaresma ${ }^{48}$.

Tratando al mundo rural de forma individualizada, podríamos establecer una relación entre ingresos y climatología. El descenso verificado en invierno podría derivar de la dureza del clima leonés y la dificultad para trasladar a los niños hasta el centro urbano; todo lo contrario ocurriría durante la primavera o el verano. En la primavera es cuando se registra la mayor intensidad de abandonos. En el mes de marzo arranca una fase alcista que culmina en mayo-junio ${ }^{49}$ : aún faltaban unos meses para recoger la cosecha, eran, por lo tanto momentos difíciles e incluso dramáticos, para los que vivían directamente del campo y no mucho más benignos para los que dependían indirectamente de él. Por otro lado, a esta institución llegaban numerosos niños procedentes de la montaña. Precisamente en esa zona los niveles más altos de concepciones corresponden a los inicios del verano, cuando regresaban los pastores. Asimismo, no debemos

48. Rubio PÉRez, Laureano M., La Bañeza y su tierra... p. 173. BARTOlomé BARTOlomé, Juan Manuel, Vino y viticultores... p. 289; PÉREZ Álvarez, María José, La montaña Noroocidental leonesa ... p. 289.

49. Este patrón es idéntico al asturiano, máximos de marzo a mayo y mínimos en diciembre y agosto. ANSÓN Calvo, María del Carmen, «Niños ilegítimos y niños expósitos en las Asturias... Se repite también en otros centros asistenciales, como Ponferrada o Santiago; e incluso guarda relación con los nacimientos ilegítimos de La Bañeza. Blanco Villegas, María José y Otros, «Exposición y muerte de los niños acogidos en la Casa Cuna de Ponferrada entre 1850-1932 (León, España)», Revista De Demografia Histórica, XX, II, 2002, 163-184, p. 173. PÉREZ GARCÍA, José Manuel, «La mortalidad infantil en la Galicia del siglo XIX....pp.196-197. RUBIO PÉREZ, Laureano M., La Bañeza y su tierra ... p. 166 
olvidar el marco en que fueron concebidos esos niños, que coinciden con los meses de mayor intensidad festiva en la provincia ${ }^{50}$ y con unas despensas que se estaban cargando. La confluencia de tan favorables circunstancias evitaría pensar a los futuros padres en las posibles consecuencias. Pero, quizás, en el máximo estacional de la ciudad, también debamos tener en cuenta el tránsito de asturianos, gallegos ${ }^{51}$ y demás trabajadores temporeros, que se dirigían a la siega en Tierra de Campos. Estas gentes podían aprovechar el paso por los centros urbanos para abandonar a sus hijos, posiblemente víctimas de las circunstancias económicas.

En un nivel intermedio aparecen el verano y el otoño, meses en los que no suele haber dificultades económicas. Los abandonos de los recién nacidos en el otoño se correspondían con las concepciones invernales, muy elevadas en algunas zonas de León $^{52}$, como consecuencia del receso laboral. Por otro lado, en agosto, concretamente, es cuando tenía lugar el mínimo de ingresos ante la bonanza económica -la cosecha estaba recogida o a punto de entrar en la despensa- y el descenso de nacimientos. Los alumbramientos del verano se corresponden con las concepciones de los meses de otoño, las cuales, en aquellas comarcas donde se cultivaba el viñedo, se resienten en octubre y noviembre, meses de gran actividad laboral ${ }^{53}$.

\section{EL FUTURO DE LOS NIÑOS INGRESADO EN LA OBRA PÍA}

Los contemporáneos eran plenamente conscientes de que una vez que los niños atravesaban el umbral de un hospicio, sobre su destino comenzaba a planear con mayor intensidad la sombra de la muerte ${ }^{54}$. Esta terrible certidumbre acompañaba también a los propios padres de la criatura y así lo testimoniaban en algunas de las cédulas con que acompañaron a sus hijos ${ }^{55}$. En la Obra permanecían, amamantados por nodrizas internas, el tiempo justo que se tardaba en encontrar un ama para la crianza fuera del Arca $^{56}$. Amas, una y otras, que no pocas veces se descubrió que eran la madre de alguno de los niños expuestos.

50. De La Fuente Galán, María del Prado, Marginación y pobreza en la Granada....p. 96. CAVA LÓPEZ. Gema, Infancia y sociedad en la Alta Extremadura durante el Antiguo Régimen, Institución Cultural El Brocense, Cáceres, 2000, p. 104.

51. Posiblemente, desde 1775 los ingresos de niños gallegos hubieran descendido, ya que en esa fecha se creó la Casa de Expósitos de Ponferrada, y sus padres, al tener que atravesar tierras bercianas antes de llegar a León, posiblemente los dejarían allí. LÓPEZ CANEDO, Ramón, Expósitos e ilegítimos... p. 121

52. PÉrez Álvarez, María José, La montaña Noroocidental leonesa ... p. 289.

53. BARTOlOmé BARTOlomé, Juan Manuel, Vino y viticultores... p. 287.

54. La mortalidad en este colectivo podía ser tres veces superior, e incluso más, que en otros grupos sociales. PÉREZ MoREDA, Vicente, Las crisis de mortalidad en la España interior (XVI-XIX), Siglo XXI, Madrid, 1980, p. 455.

55. En una cédula de 1740, dejaron anotado: «que Dios te haga más feliz en el morir que te hizo en el nacer....». Libros de Registro de Entradas del Arca de Misericordia.

56. En 1704, anotan que en la casa había tres amas para cuidar a los niños que regresan de las crianzas y «a los que echan mientras se busca ama». Libros de Registro de Entradas del Arca de Misericordia. 


\section{Grafico $n^{0}$ 5. Trayectoria de los niños ingresado en la Obra Pía (1700-1791)}

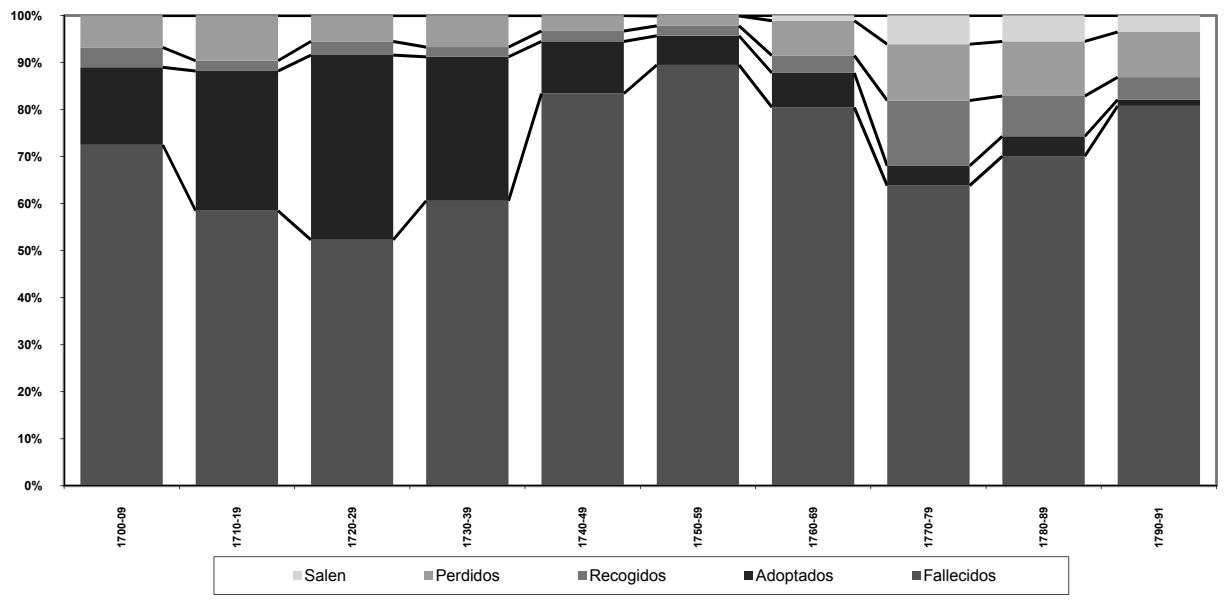

Fuente: Libros de Registro de Entradas del Arca de Misericordia

Pocos fueron los abandonados que sobrevivieron a ambas etapas, porque si en los hospicios tenían que luchar contra la fácil propagación de las infecciones infantiles, cuando salían a criar se exponían a los riesgos de contagio de enfermedades muy frecuentes entre las clases populares, en las que la falta de higiene y el hacinamiento, sobre todo en la ciudad, eran la nota predominante. De los que sobrevivieron, unos regresaron a su hogar familiar, otros fueron acogidos por familias adoptivas e incluso algunos consiguieron alcanzar la edad suficiente como para incorporarse al mercado laboral.

A través del grafico $\mathrm{n}^{\circ} 5$ y de la tabla $\mathrm{n}^{\circ} 2$, podemos conocer como evolucionaron esos destinos. Hasta donde hemos podido seguir a los niños, el porcentaje medio de fallecidos, respecto a los ingresados, fue de $71,1 \%$. Si en el calculo prescindimos de los que se perdieron, la mortandad sería del 77\%; y si además omitimos los que fueron recogidos, y nos ceñimos exclusivamente a los que desarrollaron su ciclo vital al amparo de la Obra, la cifra de expirados asciende al 81,5\% ${ }^{57}$. Esa cifra global sufrió a lo largo de la serie oscilaciones muy bruscas. Las tasas más elevadas de mortandad se

57. Se trata de una cifra muy optimista si la comparamos con Pamplona, donde entre 1791 y 1795 fallecieron el 99,2\% de los ingresados; la de Sevilla, el 84,5\%, en el siglo XIX; o la de Madrid, el 90\%, en los primeros años del siglo XIX. VALVERDE LAMSFUS, Lola, Entre el deshonor y la miseria. Infancia abandonada en Guipúzcoa y Navarra. Siglos XVIII y XIX. Universidad del País Vasco, Bilbao, 1994. p. 203. ÁlVAREZ SANTALÓ, León Carlos, Marginación social y mentalidad en Andalucía Occidental. .... SHERWOOD, Joan, «El niño expósito, cifras de mortalidad en una inclusa del siglo XVIII», Anales del Instituto de Estudios Madrileños, 1981, 18, pp. 299-312. 
constatan entre 1740 y 1769 y en 1790-1791. Por el contrario, en un cálculo parcial, entre 1710 y 1740 , el porcentaje de fallecidos se sitúa en torno al $60 \%{ }^{58}$.

Tabla $n^{0}$ 2. Trayectoria de los niños dentro de la Obra Pía

\begin{tabular}{|c|c|c|c|c|c|c|c|}
\hline & Ingresos & \multicolumn{7}{|c|}{ Porcentajes } \\
\cline { 3 - 8 } & & Fallecidos & Adoptados & Recogidos & Perdidos & Adultos & TOTAL \\
\hline $1700-09$ & 643 & 72,5 & 16,5 & 4,2 & 6,8 & & 100 \\
\hline $1710-19$ & 721 & 58,5 & 29,7 & 2,2 & 9,6 & & 100 \\
\hline $1720-29$ & 723 & 52,3 & 39,3 & 2,9 & 5,5 & & 100 \\
\hline $1730-39$ & 851 & 60,6 & 30,6 & 2,1 & 6,7 & & 100 \\
\hline $1740-49$ & 1011 & 83,5 & 11,1 & 2,2 & 3,3 & & 100 \\
\hline $1750-59$ & 942 & 89,5 & 6,2 & 2,1 & 2,1 & 0,1 & 100 \\
\hline $1760-69$ & 1049 & 80,4 & 7,3 & 3,7 & 7,4 & 1,1 & 100 \\
\hline $1770-79$ & 1362 & 63,9 & 4,2 & 13,9 & 12,0 & 6,1 & 100 \\
\hline $1780-89$ & 972 & 70,1 & 4,2 & 8,6 & 11,6 & 5,5 & 100 \\
\hline $1790-91$ & 229 & 80,8 & 1,3 & 4,8 & 9,6 & 3,5 & 100 \\
\hline
\end{tabular}

Fuente: Libros de Registro de Entradas del Arca de Misericordia

Tabla $n^{0}$ 3. Lugar de fallecimiento

\begin{tabular}{|c|c|c|c|c|}
\hline & $\begin{array}{c}\text { Antes de salir a } \\
\text { criar }\end{array}$ & Crianzas & $\begin{array}{c}\text { Regreso de las } \\
\text { crianzas }\end{array}$ & \\
\hline $1700-09$ & 46,6 & 45,7 & 7,7 & 100 \\
\hline $1710-19$ & 34,1 & 58,8 & 7,1 & 100 \\
\hline $1720-29$ & 28,0 & 69,6 & 2,4 & 100 \\
\hline $1730-39$ & 24,2 & 63,8 & 12,0 & 100 \\
\hline $1740-49$ & 44,9 & 42,7 & 12,4 & 100 \\
\hline $1750-59$ & 73,0 & 20,6 & 6,4 & 100 \\
\hline $1760-69$ & 51,0 & 36,9 & 12,1 & 100 \\
\hline $1770-79$ & 33,8 & 57,9 & 8,3 & 100 \\
\hline $1780-89$ & 44,3 & 48,9 & 6,8 & 100 \\
\hline $1790-91$ & 43,2 & 50,3 & 6,5 & 100 \\
\hline
\end{tabular}

Fuente: Libros de Registro de Entradas del Arca de Misericordia

A la vista de los porcentajes de mortalidad obtenidos, de nuevo podemos dividir la serie en tres etapas. Una primera iría desde 1700 hasta 1739. Al ser pocos los días que los niños permanecían en la institución a la espera de encontrar un ama de cría

58. Estas oscilaciones son muy frecuentes. Por ejemplo, en Madrid, la cifra global de mortalidad fue de $83,63 \%$, y, en cambio, la obtenida en el primer quinquenio del siglo XIX, fue de $61,30 \%$. ZARAGOZA RUBIRA, José R. «Aproximación al estudio de los hospicios españoles en la primera mitad del siglo XIX», Medicina Española, LII, 1964, pp. 85-92.; Para Salamanca vid. FERNÁndeZ UGARTE, María, Expósitos en Salamanca... p. 121 


\section{Gráfico n 6. Media de días que permanecen en la Obra Pía en función de la década de ingreso (1700-1791)}

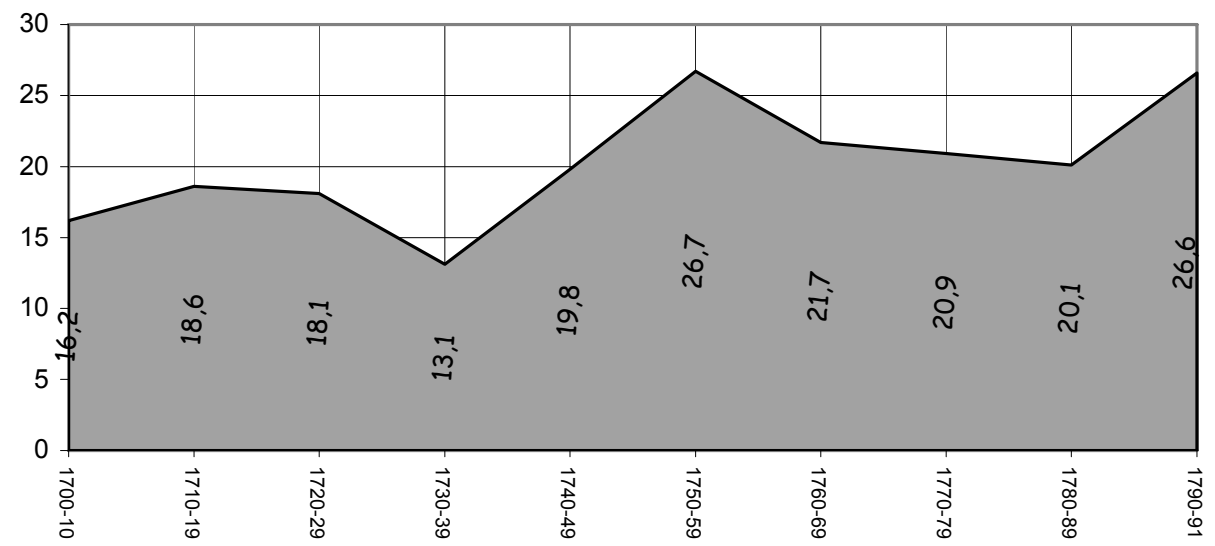

Fuente: Libros de Registro de Entradas del Arca de Misericordia

-entre 13,1 y 18,6 (Gráfico ${ }^{\circ}$ 6)-, no se constata una gran mortandad dentro de la obra -se movió entre el 24,2\% y el 46,6\% (Tabla $n^{\circ} 3$ )-. De este modo, la mayoría de los óbitos tuvieron lugar durante las crianzas, siendo la etapa más crítica la primera salida: entre el 45,7 y el 69,6\% de los niños fallecieron durante ese ciclo. A pesar de ser muy aparatosas las cifras que se desprenden de las crianzas, no las consideraríamos excesivamente alarmantes, si no fuera por la mortandad añadida que se producía en el Arca. Hemos de tener en cuenta que las defunciones infantiles de los criados por sus familias, dependiendo de las fechas y lugares, no estuvieron muy alejadas de éstas ${ }^{59}$. De todas formas, con ello no queremos eximir la picaresca a la que podía prestarse la situación de criar niños a cambio de dinero. Quizás casos como el de una mujer de Fresno del Camino, detectado a tiempo, fueran más frecuentes de lo que refleja la documentación. El 15 de mayo de 1777, se anota que cuando esa nutriz iba a marchar con una niña para criar los responsables del Arca descubrieron que no tenía leche, de no haber cumplido éstos con su obligación, la niña hubiera salido de la Obra y la nodriza intentaría tenerla viva el mayor tiempo posible para poder $\operatorname{cobrar}^{60}$, pero con un alimentación tan perniciosa que no le aseguraría esa fuente de ingresos durante mucho tiempo.

Por otro lado, en esos cuarenta años es donde se concentran la mayoría de las adopciones, con una media de 21,6 por año. Se trata de niños que una vez acabado el

59. Vid. PÉRez MoredA, Vicente, Las crisis de mortalidad en la España interior... p. 146 y ss.. Para La Bañeza, RuBio PÉREZ Laureano Manuel, La Bañeza y su tierra ... p. 175.

60. De La Fuente GalÁn, María del Prado, Marginación y pobreza en la Granada.... p. 214. «E1 niño de la Casa-Cuna es para el ama un instrumento con el que puede ganar dinero, un negocio, aunque sea mísero»». 


\section{Gráfico no 7 . Edad media a la que finalizaron los la crianza externa (1700-1791)}

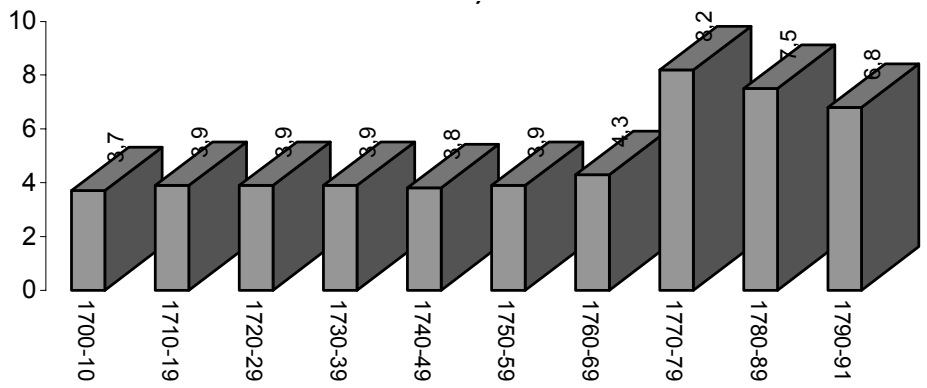

Fuente: Libros de Registro de Entradas del Arca de Misericordia.

periodo externo, el mismo día de regreso o pocos días después, son entregados a una familia. Estos pequeños accedían a la adopción en torno a los 4 años, edad fijada por la institución, durante estas fechas, como final de la crianza externa (Gráfico $n^{0} 7$ ). A partir de entonces les perdemos la pista, pero resulta bastante factible que la mayoría de ellos falleciesen en su nuevo hogar, teniendo en cuenta la vulnerabilidad de estos pequeños a tan tierna edad. De hecho, la totalidad de los niños que no encontraron familia de acogida y que, por tanto, se vieron obligados a regresar al Arca, falleción ${ }^{6}$. La media de óbitos de este tipo, durante esta fase, fue de 3,4 por año.

En estos años el porcentaje de niños de los que desconocemos su destino, oscila entre el 5,5, de 1720-29, y el 9,6, de 1710-19. De éstos, el 55,8\%, se nos extravían durante las crianzas y los demás en la Casa de Expósitos -algunos de ellos no tenemos constancia de que lleguen a salir a criar $(14,4 \%)$ y al resto perdemos su pista al regreso del periodo externo, bien finalizado $(23,6 \%)$ o sin llegar a completarlo $(6,2 \%)$ Es muy complicado dar una explicación del por qué se produce esa falta de noticias, cuando el control parecía ser muy exhaustivo. Podría deberse a la muerte, el rescate o adopciones. Quizás en el caso de los niños que finalizan con éxito la crianza el destino hemos de buscarlo en las calles de León, donde la Obra, al carecer de recursos, los abandonaba, a los siete años, a pedir limosna ${ }^{62}$.

Una segunda etapa iría de 1740 a 1769 . La media de ingresos es de 100,1 niños/ año, lo que supone un incremento del $30 \%$ respecto a la etapa anterior. En esa media, como hemos visto, tuvieron mucho que ver los niños llegados de fuera de la ciudad. Durante estos decenios los porcentajes globales de mortalidad con respecto a las entradas se mueven entre el $80,4 \%$ de $1760-1769$ y el $89,5 \%$ de $1750-1759$, es decir, a unos niveles significativamente superiores a los de la anterior etapa. Se tardaba más en

61. El que se apunte en la partida la causa de muerte es excepcional. Sólo en dos casos sabemos que fue el tifus el causante del óbito.

62. Villacorta Rodríguez, Tomás, El Cabildo de la Catedral de León ..... p. 450. 
encontrar ama externa para amamantar a los infantes, concretamente en la década en la que se registró una mayor mortandad, 1750-59, la espera llegó a ser de 26,7 días ${ }^{63}$. Esto supuso que el $73 \%$ de los ingresados en esos diez años fallecieran antes de salir a criar. Hasta entonces nunca se habían registrado volúmenes de ingresos tan elevados. Por lo tanto, el aumento de las cifras de mortandad sería consecuencia de la fuerte presión que se estaba ejerciendo sobre la infraestructura asistencial de una fundación que no estaba preparada para absorber a tantos niños, traduciéndose en un hacinamiento que pocos podían superar. Esas elevadas tasas de mortandad, lógicamente, redujeron las adopciones, que descendieron a 13,9 por año. Tengamos en cuenta que en este ciclo existen dos décadas de graves dificultades económicas para la provincia: la de 174049 y la de 1760-69. En esos años de obstáculos se obtienen también elevadas cifras de mortandad entre los niños que acaban la crianza y que, al no encontrar una familia de acogida, han de ingresar de nuevo en la obra. Fallecen víctimas de esta circunstancia entre 10,5 y 10,2 niños por año, respectivamente, cuando la media de la serie es de 5,7. Fue esta situación tan apurada la que llevó al Arca de Misericordia a solicitar a la Corona un auxilio económico, concretamente el mismo que ya había sido otorgado a otras instituciones similares en fechas precedentes: el maravedí sobre el azumbre de vino. Esta concesión le proporcionó el suficiente desahogo económico como para permitir la prolongación del contrato de las nodrizas, así como el aumento de su salario. Tales medidas repercutieron de forma positiva en las condiciones de vida de los pequeños que, al menos, lograron prolongar su estancia terrenal. De hecho, podemos apreciar como en la década de los setenta, de nuevo, comenzaron a descender los porcentajes de niños que fallecían sin salir de la obra y aumentaron los óbitos durante las crianzas.

La tercera etapa engloba desde 1770 a 1791 . Durante estas décadas la media de niños ingresados por año continuó creciendo con respecto a los años precedentes. Los 116,5 que se registran en este momento significan un incremento del 58,5\% respecto a las cuatro primeras décadas de la centuria y del $16,4 \%$ en relación a las centrales. Estos veintidós años muestran evidentes similitudes con el ciclo anterior en cuanto al período temporal de espera por un ama externa, que se sitúa en torno a los 20-21 días. La mortandad se mantiene en niveles intermedios a los ya vistos, oscilando entre el $63,9 \%$ de $1770-1779$ y el $80,8 \%$ de $1790-1791$. Los resultados no son pues tan optimistas como en los primeros decenios de la centuria ni tan negativos como los de la etapa precedente. Asimismo, volvemos a constatar una mayor letalidad durante el período de crianza externa, como ya sucedía en la primera etapa. Es a estas alturas del siglo cuando comienza a cobrar fuerza la asistencia del Arca a los niños depositados. Al mejorar la situación económica de la casa, ésta abre sus puertas a la recepción de niños confia-

63. Se confirma en León lo apuntado por Sherwood para Madrid. «La esperanza de supervivencia para el niño era salir del hospital lo antes posible con una nodriza». SHERWOOD, Joan, «El niño expósito, cifras de mortalidad.. p. 309. En la misma línea está ARNAU AlEMANY, Lliberada y SERNA Ros, Pedro, «La mortalidad de los niños expósitos en el Hospital General de Valencia», en BERNABEU MESTRE, Josep (coor.), El papel de la mortalidad en la evolución de la población valenciana, Diputación de Alicante, Alicante, 1991, p. 169. 
dos temporalmente por padres que no pueden costear la crianza de su hijo. La llegada de estos nuevos inquilinos es cada vez más importante y adquiere entidad en la serie, como también sucede con su posterior rescate familiar. La media de recuperaciones anuales, que habían sido en las etapas precedentes de 2,1 y 2,7 respectivamente, pasa a 12,5 en este momento ${ }^{64}$. La década en que más niños se depositaron fue la de 177079, y, de éstos, el 13,9\% volvió con sus familiares. En los dos decenios posteriores también entraron temporalmente muchos niños en la Casa de Expósitos, sin embargo, los efectos de una mortandad más cruel hizo descender a un $8,6 \%$ y un $4,8 \%$, respectivamente, los rescates. Por otro lado, el nivel de las adopciones continuó decreciendo $-4,5$ por año- debido, tanto a las dificultades económicas de la provincia ${ }^{65}$, como a la prolongación de las crianzas externas hasta los 8 años o incluso más. Posiblemente el incremento temporal de esas estancias sea la causa principal de los altos porcentajes de perdidas -entre el 9,6 y 12\%-. No sería descabellado pensar que aquellos lactantes que alcanzaron la adolescencia en el hogar de alquiler, se pudieran haber independizado de la institución e incorporado al mercado laboral. Sin embargo, el hecho de que el 84,3\% de las pérdidas se produzcan durante la crianza, y que los protagonistas de más de la mitad de éstas sean hijos de padres identificados, nos inclina a darle mayor peso a la posibilidad de un rescate familiar.

Los últimos veintidós años analizados tienen en común con el ciclo anterior la prolongación de la estancia interna, debido a la masificación de incorporaciones. Tal demora en las salidas generó importantes mortandades, aunque sin llegar a los niveles de 1740-1769. Por el contrario, parece que la mortandad fue más benigna durante los primeros cuarenta años de la serie, pero quizá, si cruzamos todas las variables, el resultado nos conduzcan a tomar con mucha precaución esos índices de aparente supervivencia. Hasta 1739, los niños que habían superado la dura etapa de espera y las crianzas, se desligaban del arca en torno a los cuatro años. En el segundo periodo, al registrarse una elevada mortandad interna, las posibilidades de alcanzar otros destinos prácticamente desaparecían. Pero en los últimos años, al ser la estancia externa más larga, tuvimos la oportunidad de seguir la evolución de los niños durante más tiempo, y comprobamos como después de los cuatro años seguían muriendo. Por lo tanto, esos bajos índices de mortandad que refleja la serie en sus comienzos no parecen reales, sino que son consecuencia de que los óbitos de los niños desligados de la obra dejan de ser competencia de ésta.

64. Es un comportamiento distinto al de Granada, donde ingresos y rescates se mueven con porcentajes inversas. De La Fuente Galán, María del Prado, Marginación y pobreza en la Granada.... p. 225.

65. Durante los años finales de la década de los sesenta y, con más intensidad, durante la de los setenta, constatamos un hecho que no hemos encontrado anteriormente ni se volverá a repetir: el Arca se vio obligada a recoger a varios niños que habían sido entregados en adopción porque sus nuevas familias no podían mantenerlos. 


\section{EDAD MEDIA DE FALLECIMIENTO DE LOS NIÑOS INGRESADOS EN LA OBRA PÍA}

Las expectativas de vida de los niños ingresados en el Arca de Misericordia de León entre 1700 y 1791 eran muy poco halagüeñas. Las criaturas eran víctimas de toda una serie de avatares que podían comenzar en el mismo momento en que la madre tenía conocimiento de su embarazo y que finalizaban, en la mayoría de las ocasiones, con una muerte prematura. El momento más crítico para su supervivencia era el primer mes de estancia, sobre todo para aquellos pequeños que no encontraban nodriza externa; un tercio de los ingresados $-33,5 \%$ - no superaban los primeros treinta días ${ }^{66}$, un $26,7 \%$ fallecía entre el primer y el tercero; y el $10,7 \%$, cumplidos los tres y antes de los seis. En consecuencia, solamente el 29,1\% lograba exceder el medio año de vida ${ }^{67}$ y el $22,3 \%$ los primeros doce meses $^{68}$. De ese minoritario sector que logró superar el umbral del año, únicamente un exiguo 3,6\% sobrepasó los seis años de edad.

Estas cifras, ya de por sí demoledoras, se recrudecen si únicamente contabilizamos a los niños que no superaron el período interno antes de salir a la primera crianza. En ese caso, más de dos tercios morían durante el primer mes, concentrándose los óbitos en la primera quincena. Por el contrario, los porcentajes descienden si nos referimos a los que tuvieron la oportunidad de encontrar una nodriza. De los que llegaron a salir, solamente fallecen en el primer mes desde su ingreso el 12,3\%. Estas diferencias ratifican, una vez más, la fuerte relación que existía entre supervivencia y crianza de alquiler.

En cuanto a la evolución de la mortalidad por etapas, los resultados muestran una evidente estabilidad, lo que da a entender que no existió ninguna mejora significativa en la calidad de vida de los niños.

66. Este porcentaje es casi similar al de Salamanca entre 1794 y $1825(31,87 \%)$ y ligeramente más bajo que el granadino (37,06\%). Torrubia BALAGUE, Eulalia, Marginación y pobreza. Expósitos en Salamanca ... p. 149; L. De La Fuente Galán, María del Prado, Marginación y pobreza en la Granada.... p. 231. Si contrastamos los fallecidos en el primer mes de vida, con los que murieron antes de cumplir el año, el resultado inicial es más benigno que el gallego pero, como veremos, esta circunstancia no es indicativa de un mayor índice de supervivencia. PÉREZ GarCíA, J. M. «La mortalidad infantil en la Galicia del siglo XIX.... p. 187.

67. Se trata de un porcentaje mayor a los obtenidos en Granada y Sevilla, donde en el siglo XVIII, sólo el $12,2 \%$ y el $20 \%$, respectivamente, sobrevivían hasta los 6 meses. DE LA FuENTE GALÁN, María del Prado. Marginación y pobreza en la Granada.... p. 231. Álvarez SANTALó, León Carlos, Marginación social y mentalidad en Andalucia Occidental... p. 172.

68. En León, la muerte es menos prematura que en Asturias, donde sólo el 19,8\%, superó el año. ANSÓN CALVO, M. C., «Niños ilegítimos y niños expósitos en las Asturias... 
Tabla n 4. Evolución por etapas de la edad de fallecimiento de los niños del Arca de Misericordia de la ciudad de León (1700-1791)

\begin{tabular}{|c|c|c|c|c|c|c|c|c|}
\hline & \multicolumn{2}{|c|}{ 1700-1739 } & \multicolumn{2}{|c|}{ 1740-69 } & \multicolumn{2}{|c|}{ 1770-1791 } & \multicolumn{2}{|c|}{ TOTAL } \\
\hline Edad & $\mathbf{N}^{\mathbf{o}}$ & $\%$ & $\mathbf{N}^{\mathbf{o}}$ & $\%$ & $\mathbf{N}^{\mathbf{o}}$ & $\%$ & $\mathbf{N}^{\mathbf{o}}$ & $\%$ \\
\hline$-1 \mathrm{mes}$ & 365 & 26,7 & 971 & 38,3 & 550 & 32,0 & 1.886 & 33,5 \\
\hline $\begin{array}{l}+1 \text { a } 2 \\
\text { meses }\end{array}$ & 181 & 13,2 & 482 & 19,0 & 282 & 16,4 & 945 & 16,8 \\
\hline $\begin{array}{l}+2 \text { a } 3 \\
\text { meses }\end{array}$ & 143 & 10,4 & 251 & 9,9 & 163 & 9,5 & 557 & 9,9 \\
\hline $\begin{array}{l}+3 \text { a } 6 \\
\text { meses }\end{array}$ & 199 & 14,5 & 210 & 8,3 & 190 & 11,0 & 599 & 10,7 \\
\hline $\begin{array}{l}+6 \text { a } 12 \\
\text { meses }\end{array}$ & 139 & 10,2 & 121 & 4,8 & 125 & 7,3 & 385 & 6,8 \\
\hline+1 a 2 años & 123 & 9,0 & 129 & 5,1 & 129 & 7,5 & 381 & 6,8 \\
\hline +2 a 3 años & 70 & 5,1 & 63 & 2,5 & 64 & 3,7 & 197 & 3,5 \\
\hline+3 a 4 años & 58 & 4,2 & 46 & 1,8 & 24 & 1,4 & 128 & 2,3 \\
\hline+4 a 5 años & 69 & 5,0 & 156 & 6,2 & 32 & 1,9 & 257 & 4,6 \\
\hline+5 a 6 años & 15 & 1,1 & 49 & 1,9 & 20 & 1,2 & 84 & 1,5 \\
\hline+6 años & 7 & 0,5 & 55 & 2,2 & 141 & 8,2 & 203 & 3,6 \\
\hline & 1.369 & 100 & 2.533 & 100 & 1.720 & 100 & 5.622 & 100 \\
\hline
\end{tabular}

Fuente: Libros de Registro de Entradas del Arca de Misericordia

En la fase de 1700 a 1739, el 26,7\% de los niños fallecían antes de los treinta días y el $13,2 \%$ en el mes siguiente, de tal forma que el $75 \%$ ya habían fallecido antes del año. A partir de ese tramo, los porcentajes comienzan, lógicamente, a descender para invertir la tendencia entre los 4 y 5 años. Es el momento en que regresan al Arca los niños que habían completado su crianza y que no resisten un nuevo proceso de inmunización.

De 1740 a 1769, la mortalidad en la base continúa siendo muy elevada. En esas décadas aumentaron mucho los ingresos y los niños debían de permanecer en al Obra Pía, a la espera de ama, más días que en la etapa anterior. Continuamos viendo como en los cuatro años hay una pequeña oscilación, marcada por el regreso al Arca de los niños criados fuera, a partir de ese tramo de edad los porcentajes que aparecen son ligeramente más altos que en el caso anterior. Lo que se debe, por un lado, a que en este periodo las adopciones fueron más bajas; pero también hemos de tener en cuenta que los niños que habían ingresado en 1768 y 1769 se beneficiaron del impuesto del vino, por lo que su crianza externa se prolongó.

En el último periodo desciende ligeramente la mortalidad en la base, volvían a salir antes a criar. Entre los 2 y 6 años, apenas existen diferencias con los porcentajes ya vistos. En cambio, a partir de los seis años encontramos unas cifras elevadas que nos podrían conducir a pensar una mayor expectativa de vida. Pero no olvidemos que en esa etapa los niños regresaban más tarde de las crianzas, de ahí los porcentajes de óbitos más elevados a partir de los seis años. 
A partir de la década los cincuenta, en que comienzan a reducirse las adopciones y el futuro de los niños comienza a estar ligado al Arca durante más tiempo, podemos calcular mejor la supervivencia. Pero el resultado, más real, no es muy alentador, tan sólo llegan a salir al mercado laborar el 3,4\% de los ingresado entre 1750 y 1791, lo cual nos sitúa ante una cifra de mortandad, de los niños dependientes del Arca, desorbitada, el 96,6\%.

\section{ESTACIONALIDAD DE LAS DEFUNCIONES}

Al distribuir la mortandad por meses, nos encontramos con tres convexidades (Gráfico $\mathrm{n}^{\circ}$ 9). La primera, y más importante, comienza en agosto y finaliza en octubre $^{69}$, y está estrechamente relacionada con las letales enfermedades padecidas por los pequeños en los meses cálidos del año -deshidratación, gastroenteritis, etc.-. Los sufrimientos ocasionados por estos males se veían agravados por la aglomeración que se producía en los centros, debido a las numerosas entradas de la primavera y el alargamiento de las estancias a la espera de nodriza (Gráfico ${ }^{\circ} 10$ ). De hecho, durante los meses de mayo, junio y julio, las criaturas se veían obligadas a permanecer algo más de un mes en los centros antes de partir hacia el hogar de alquiler, frente a lo que sucedía, por ejemplo, en febrero, en donde el tiempo de espera era poco más de medio mes. Las faenas del campo ya habían comenzado en aquellos meses veraniegos, por lo que la llegada de las criadoras se retrasaba a medida que esas labores se agudizaban ${ }^{70}$. A partir del mes de agosto comenzará a remitir el tiempo de espera para de nuevo resentirse de noviembre a enero. Esa demora de finales de otoño y comienzos de invierno, estaría vinculada, por un lado, con el inicio de la labor de siembra y, por otro, con la caída de la demanda de crianzas externas. Las mujeres protagonistas de estas actividades procedían, fundamentalmente, del mundo rural y el hecho de trasladarse a la ciudad en busca de un niño al que criar no resultaría fácil en los meses de invierno. Además, la necesidad de un salario extra, siempre bien recibido, no sería tan perentoria en estos momentos como en primavera.

Tanto el segundo de los máximos -los meses de febrero y marzo- como el tercero, ligeramente más suave que el anterior -los de noviembre y diciembre- están relacio-

69. Los tres primeros meses en que fueron más altos los índices de mortandad-septiembre, agosto y octubre-, coinciden con Salamanca. No así el cuarto, que en León tenía lugar en febrero. TORRUBIA BALAGUE, Eulalia, Marginación y pobreza. Expósitos en Salamanca (1794-1825), Diputación de Salamanca, Salamanca, 2004, p. 151. El máximo de agosto-octubre, también coincide con Asturias, así como el mínimo de abril. ANSÓN CALVO, María del Carmen, «Niños ilegítimos y niños expósitos en las Asturias...; También en Madrid, entre 1700 y 1740, los meses más letales eran los de finales de verano y otoño cuando los niños eran víctimas de enfermedades como la malaria, la gastroenteritis, etc. SHERWOOD, Joan, «El niño expósito, cifras de mortalidad... p. 309. Una mortalidad diferente la encontramos, por ejemplo, en Valencia, donde los máximos se concentran de abril a julio. ARNAU ALEMANY, Lliberada y SERNA Ros, Pedro, «La mortalidad de los niños expósitos.. p. 163.

70. ARnAu Alemany, Lliberada y Serna Ros, Pedro, «La mortalidad de los niños expósitos.. p. 168-9. En Valencia los meses de máxima ocupación del hospicio y también de mortandad, fueron los de verano, debido a la mayor tardanza en la búsqueda de nodriza. 


\section{Gráfico n 9. Estacionalidad de los fallecimientos de los niños que no han salido} a una crianza externa en el Arca de Misericordia de la ciudad de León (1700-1791)

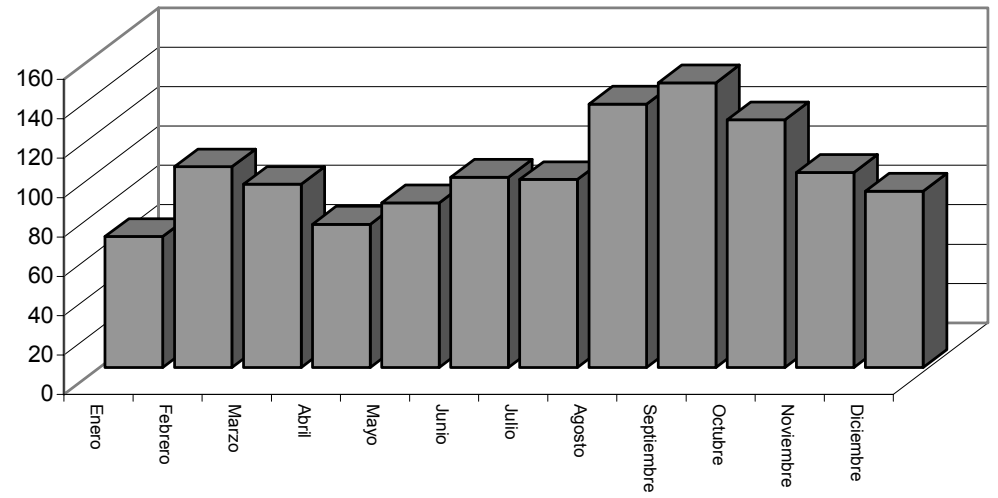

Fuente: Libros de Registro de Entradas del Arca de Misericordia

\section{Gráfico n 10. Media de días que permanecen en le Obra Pía antes de salir a criar en función del mes de ingreso (1700-1791)}

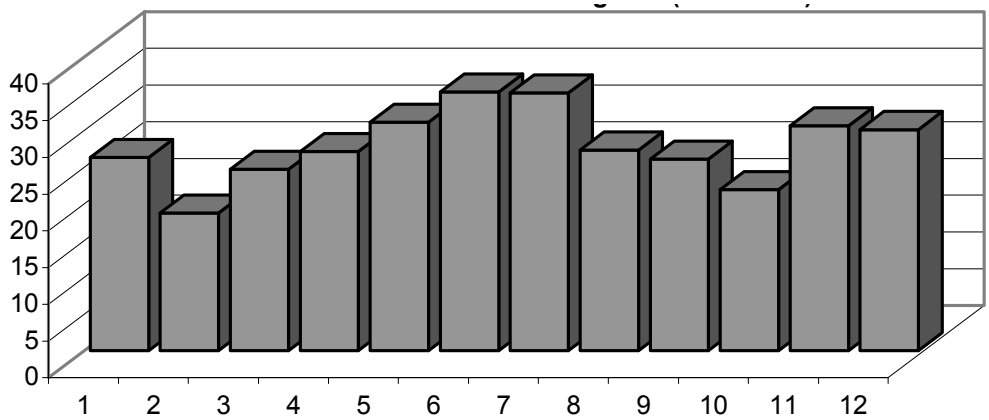

Fuente: Libros de Registro de Entradas del Arca de Misericordia

nados entre sí. Corresponden a los meses más fríos del año, lo que unido a las precarias condiciones de vida de las criaturas custodiadas en los establecimientos leoneses, provocaría esa subida de la mortalidad. Este panorama más o menos uniforme se ve bruscamente alterado en enero. Tal comportamiento es consecuencia del retraimiento de las entradas durante ese mes y el precedente. Frente a estas etapas críticas, los mínimos coinciden con la benignidad de la primavera y el despertar de la afluencia de las nodrizas a las casas.

Acabar señalando que las causas que llevaron a los progenitores al abandono de niños fueron muy variadas: la ilegitimidad y el honor familiar, la miseria, la orfandad, 
etc. Valorar en que medida tuvieron más peso unas que otras es muy difícil ${ }^{71}$. Las cédulas, cuando lo reflejan, no nos ayudan mucho a esclarecer el por qué del abandono. La mayor parte son muy ambiguas, otras incompletas, sin olvidar la impunidad que da el anonimato para anotar la versión que consideraban más podía conmover a la Institución.

Los ingresos de niños en el Arca de Misericordia de la ciudad de León fueron aumentando a lo largo del siglo XVIII, sobre todo en la segunda mitad. Esas entradas, al igual que demostraron otros trabajos, describen una curva que tiene cierta vinculación, que no una superposición perfecta, con las crisis de subsistencia y los avancesretrocesos demográficos.

Los niños eran abandonados a lo largo de todo el año, pero sobre todo en primavera, cuando las despensas habían bajado a los mínimos anuales, y estaban condenados a morir. Precisamente en esta circunstancia se apoya gran parte del desarrollo del presenta trabajo. Los porcentajes de mortalidad que obtenemos en algunos momentos, respecto al total de los ingresados, pueden resultar optimistas, pero de ninguna manera reales, al estar condicionados por todos aquellos niños que, de una forma u otra, salen del ámbito de competencias de la Institución. Por el contrario, si prescindimos de los «liberados», el porcentaje de niños que falleció en la Casa de Expósitos de León es tan elevado, incluso más, que el constatado en otros trabajos. A ese nefasto futuro hemos de añadir la brevedad del periplo vital. Ese fracaso, que no se puede relativizar de ninguna forma, quizá fuera para los niños el alivio de los padecimientos terrenos (hambre, enfermedad, falta de cuidados...).

71. Vid. ALVERDE LAMSFus, Lola, Entre el deshonor y la miseria..... p. 77. 